\title{
CUIDADO DO LACTENTE NO PRIMEIRO ANO DE VIDA CONHECIMENTOS DESEJADOS POR UM GRUPO DE MÃES
}

\author{
Rosemary Ribeiro Lindholm
}

LINDHOLM, R. R. Cuidado do lactente no primeiro ano de vida - conhecimentos desejados por um grupo de mães. Rev. Bras. Enf., Brasília, 37(1): 36-43, 1984.

\begin{abstract}
RESUMO. O objetivo principal deste estudo foi verificar os conhecimentos que as mães de crianças de zero a um ano de idade gostariam de receber para cuidar de seus filhos. Foram entrevistadas 110 mães primíparas, matriculadas num centro de saúde, na cidade de São Paulo. Os conhecimentos requeridos pelas mães por ordem decrescente foram alimentação, manifestações orgânicas ou afecções comuns da infância, desenvolvimento, higiene corporal, crescimento, sono, imunização, necessidades afetivas e higie ne do ambiente. Constatou-se, ainda, que quanto mais baixa a idade da criança maior o número de solicitações apresentadas pelas mães. Os resultados desta pesquisa podem ser aplicados eventualmente em centros de saúde, mas de maneira criteriosa, para evitar generalizações que, provavelmente, iriam contrariar as necessidades individuais de aprendizagem das mães.
\end{abstract}

\begin{abstract}
The principal objective of this study was to verity the mother's knowledge, of children between zero and one year old, want to obtain to care their child. The author interviewed 110 primipara mothers, in health center, in São Paulo. The desirable knowledge, in decreasing sequence were nutrition, organic manifestation or common disease during childhood development of child corporal hygiene, growth, sleep, vaccination, emotional needs and environment hygiene. The author, obtained that mother of younger child needed more information. The results of this survey can be generalized with restriction because the individual needs must be considered.
\end{abstract}

\section{INTRODUÇAO}

Muitos autores têm enfatizado a importância do controle de saúde do grupo materno-infantil. O Ministério de Saúde, V Conferência Nacional de Saúde 6 , considerou esse grupo prioritário para efeito das ações integradas de saúde por constituir uma parcela ponderável da população brasileira $(70,98)$ e caracterizarse por condições biopsicossociais que 0 torna mais vulnerável aos riscos de adoecer e morrer.

PUFFER \& SERRANO ${ }^{17}$, relatando os resultados da Investigação Interamericana de Mortalidad de la Niñez, que tinha como objetivo verificar o coeficiente de mortalidade infantil, no grupo de maiores de cinco anos, informaram que dos 35.095 óbitos ocorridos, $78,6 \%$ eram de menores de um ano.

LAURENTI $^{11}$, baseando-se no mesmo estudo, comentou que a mortalidade infantil no Estado de São Paulo é "excessivamente alta" (65 por 1.000 nascidos vivos), considerando o nível de desenvolvimento desse Estado. Segundn o autor, as causas que contribuem para esse alto índice de mortalidade são as doenças infecciosas, no período infantil e neonatal, destacando-se, entre elas, a diarréia, com $81,4 \%$ e $81,3 \%$ nos grupos de crianças menores de um ano e menores de 28 dias, respectivamente. Como causas subseqüentes, 0 autor menciona o sarampo, a difteria, a coqueluche e o tétano, responsáveis por $6 \%$ da mortalidade infantil. A desnutrição presente em $28 \%$ dos óbitos de menores de um ano, constitui outra causa básica ou associada de mortalidade.

$\mathrm{O}$ autor considera que a grande maioria dos óbitos poderia ter sido evitada com a melhoria das condições de abastecimento de água e da rede de esgoto e com um eficiente programa de vacinação contra o sarampo. Destaca também a "necessidade de uma programação global e integrada que envolva, entre outros aspectos, a nutrição, o saneamento do meio, a educação, a assistência pré-natal, a amamentação natural dos recém-nascidos e a vacinação".

JELLIFE $^{10}$ afirma que a maioria das enfermidades das crianças dos países tropicais

1. Professor Assistente da Universidade Federal do Maranhão. COREn-MA 6367. 
pode ser prevenida mediante a utilização de métodos de grande escala, principalmente, 0 da educação sanitária.

De um modo geral, os autores estudados são unânimes em afirmar a importância dos programas de educação sanitária, como um dos meios de diminuir a taxa de mortalidade infantil.

BLAKE" ressalta que "a orientação aos pais, nos primeiros anos de vida da criança, é essencialmente necessária, sob o ponto de vista da prevenção antecipada de defeitos físicos e distúrbios emocionais". PUFFER \& SERRANO concordam cum essa afirmação quando alegam que o primeiro ano de vida é um período decisivo da vida da criança para que se possa contar com populações sadias e inteligentes.

DU $\mathrm{GAS}^{8}$ afirma que, há algum tempo, a enfermeira, como membro da equipe de saúde, vem atuando na área da educação com papel de destaque, ajudando a satisfazer a necessidade de aprendizagem do ser humano.

A Comissão Nacional para o Estudo de Enfermagem e Educação de New York, citada por BRINTON \& OGDEN ${ }^{14}$ sugere que as enfermeiras devem fazer parte integral do sistema de fornecimento de assistência à saúde, tanto nos moldes tradicionais, como num tipo de assistência preventiva mais completo.

O Comitê de Expertos da OPS/OMS ${ }^{15}$ classificou as funções do enfermeiro, nos Programas de Saúde Materno-Infantil, em quatro áreas: área assistencial, área educativa, área administrativa e área de pesquisa. $\mathrm{Na}$ área educativa, o enfermeiro participa com a equipe de saúde, na identificação das necessidades de aprendizagem dos pais, crianças e adolescentes, como também, na planificação, desenvolvimento e avaliação de programas educativos para esse grupo. Isso inclui campanhas educativas de prevenção de enfermidades, ensino de hábitos alimentares e higiênicos, educação sexual, educação para a vida familiar e ensino da mãe no cuidado de si mesma e de sua criança.

OGUISSO \& SCHMIDT $^{16}$ mostram, em seu trabalho, que uma das principais tarefas do enfermeiro puericultor e pediátrico, entre outras, é auxiliar os familiares da criança no reconhecimento das suas necessidades por meio de entrevistas de orientação para manutenção ou recuperação de sua saúde.

MARLOW ${ }^{13}$ enfatiza que o enfermeiro é o profissional "que pode contribuir de diversos modos para melhorar a saúde física e mental do lactente e das crianças de mais idade", podendo intervir através da educação, tanto nas relações saudáveis entre os pais e os filhos, como nas questões de desenvolvimento físico e emocional da criança e seu cuidado sanitário.

Entretanto, a autora acima citada, chama a atenção dos enfermeiros, para um aspecto que deve ser considerado na educação dos pais, que é o seguinte: "em cada comunicação que tenha o enfermeiro com os pais, deve haver um objetivo definido, porém, $o$ interesse dos pais deve ser averiguado antes de dar-se informações. Pois, se os pais não se interessarem pelo assunto, pouco se ganhará com a entrevista".

Por outro lado, DU GAS ${ }^{8}$ também destaca que a aprendizagem é mais eficaz quando constitui uma resposta a uma necessidade que 0 indivíduo sente. RIDDLE ${ }^{18}$ concorda com esta afirmação quando diz: "em geral o aconselhamento dos pais é mais eficiente quando ele começa com assuntos e preocupações que os pais expressam".

Pelo exposto, pode-se considerar que a preocupação do enfermeiro, em identificar inicialmente o que a mãe deseja aprender constitui a base fundamental para a interação mãe-criança-enfermeiro e o primeiro passo para a satisfação das necessidades de aprendizagem das mães.

Com este estudo, espera-se contribuir para a melhoria da assistência de enfermagem ao lactente, através de orientações que correspondam, na medida do possível, às necessidades de aprendizagem das mães, e, simultaneamente, despertar o interesse dos enfermeiros para outras pesquisas sobre $o$ assunto.

\section{OBJETIVO}

O principal objetivo desse estudo foi verificar os conhecimentos que as mães dos lactentes, no primeiro ano de vida, desejam obter para cuidar de seus filhos e, secundariamente, averiguar se esses conhecimentos variam de acordo com a idade da criança.

\section{METODOLOGIA}

\section{Local}

O estudo foi realizado em um centro de saúde localizado na Capital de São Paulo.

\section{População}

A população foi composta por mães de crianças com idade de zero a doze meses, que freqüentavam o referido serviço desde o prénatal. 


\section{Critérios para a seleção da população}

Os critérios utilizados para a seleção da população foram os seguintes:

- Mães com idade entre 15 e 45 anos, visto que a maioria das mães que freqüentava o centro de saúde, está incluída nesta faixa etária;

- Mães primíparas com filho em idade entre zero e doze meses, nascidos a termo de parto normal. Com isto tentou-se evitar a influência de experiências anteriores, nas respostas dadas, tanto no que diz respeito ao tipo de parto como nos cuidados com outros filhos;

- Mães que cuidavam do filho. Esta escolha deve-se à suposição de que as mães que cuidam de seu próprio filho têm maior necessidade de aprendizagem do que aquelas que delegam o cuidado da criança a outras pessoas;

- Mães de crianças atendidas pelo Programa de Saúde do Centro de Saúde onde foi realizada a pesquisa.

\section{Tamanho da amostra}

A população estudada constituiu-se de 110 mães, selecionadas segundo os critérios acima descritos e que compareceram ao centro de saúde no período correspondente à coleta de dados.

\section{Método}

\section{Coleta de dados}

Os dados foram coletados por meio de entrevistas individuais, aplicando-se um formulá rio com perguntas abertas que abordavam dados pessoais da mãe, da criança e uma questão sobre que orientação a mãe gostaria de receber para cuidar da criança.

A fim de verificar o interesse da mãe pelo tipo de conhecimento que desejava obter, depois de ter sido dada a informação, perguntava-se o porquê? Presume-se que, se a mãe apresentava uma justificativa pertinente, era porque estava realmente preocupada em obter aquele esclarecimento.

A validade do instrumento de coleta de dados foi comprovada por meio de um teste piloto, realizado junto a quinze mães, selecionadas pelo mesmo critério já descrito anteriormente.

A coleta de dados definitiva foi realizada no período de 11 a 28 de setembro de 1978 , nos horários que antecediam à consulta médica. Com isto tentou-se evitar as respostas dadas pelas mães fossem influenciadas pela consulta do dia. O tempo gasto, em cada entrevista, foi de 15 minutos em média.

\section{Tratamento dos dados}

Após a coleta de dados, agruparam-se as respostas dadas pelas mães em áreas de conhecimento $e$ as justificativas das mães para cada tipo de conhecimento desejado foram reunidas em categorias.

A análise dos dados obtidos foi feita somente em relação à sua porcentagem, sem qualquer outro tratamento estatístico.

\section{Critérios para classificação das respostas}

As respostas dadas foram classificadas de acordo com as áreas de conhecimentos descritos a seguir.

\section{Alimentação}

Nesta área se incluem vários aspectos relacionados à alimentação da criança no primeiro ano de vida, como importância da alimentação natural, técnica da amamentação, duração das mamadas, alimentação artificial: tipos de leite, técnica no preparo das fórmulas alimentícias, oferta de água, suco, chá, higiene no preparo dos alimentos, alimentação mista e introdução de novos alimentos como papa de frutas, refeição de sal (sopas) e refeições sólidas.

\section{Manifestações orgânicas ou afecções comuns na infância}

Aqui foram incluídos os conhecimentos desejados pelas mães que tivessem relação com identificação, causas, prevenção e cuidados com a criança, nas diversas manifestações orgânicas ou afecções comuns no primeiro ano de vida. Considerou-se neste estudo como manifestações orgânicas, todos os sinais e sintomas não patológicos da criança e como afecções, os patológicos. Contudo, não sendo possível fazer-se um estudo sobre os sinais e sintomas das crianças, citados pelas mães, resolveu-se agrupar numa mesma área de conhecimento, tudo que se relacionasse às manifestações orgânicas ou afecções comuns na infância.

\section{Higiene corporal}

Os conhecimentos agrupados nesta área se referem aos aspectos citados por MARLOW ${ }^{13}$ quanto aos cuidados diários do lactente, ou seja, banho, cuidados com a pele, passeios, banho de sol, exposição ao ar livre, vestuário e maneira de carregar a criança (transporte).

\section{Crescimento}

Para classificação dos conhecimentos relacionados com o crescimento foram considera- 
dos os aspectos de aumento de peso, de altura e manifestações relativas à dentição, citados por MARCONDES ${ }^{25}$.

\section{Imunização}

Nesta área, foram incluídos os conhecimentos desejados pelas mães, sobre a importância das vacinas, idade para o seu emprego, contra-indicações, reações e período de proteção da vacina.

\section{Desenvolvimento}

A inclusão nesta área dos conhecimentos desejados pelas mães teve como base o critério de GESELL \& AMATRUDA $^{9}$ para estudar o desenvolvimento da criança.

Conduta motora é considerada a capacidade da criança desenvolver os grandes e pequenos movimentos corporais e as coordenações motoras: reações posturais, sentar, engatinhar, andar, forma de aproximar-se de um objeto e manejá-lo.

Conduta adaptativa trata-se da capacidade da criança executar as delicadas adaptações sensório-motoras frente a objetos e situações, e a coordenação de movimentos oculares e manuais para alcançar e manipular objetos e situações novas.

Conduta da linguagem inclui o sentido mais amplo da comunicação: comunicação visual, audível, gestos, movimentos posturais, vocalização, palavras ou orações. Inclui também imitação e compreensão do que expressam as pessoas.

Conduta pessoal-social compreende as reações pessoais da criança, diante da cultura social do meio no qual ela vive. Porém, como explica o autor ${ }^{9}$, muitas das reações da criança incluídas nesta conduta, estão determinadas por fatores intrínsecos da maturação fisiológica. Por exemplo, cita miç̧ão e defecação como exigências culturais do meio, porém sua aquisição depende primariamente da maturação neuro-motora, o mesmo ocorrendo à capacidade de alimentar-se por si só, higiene, independência no jogo, colaboração e reação adequada ao ensino e às convenções sociais.

Incluíram-se também nesta área os conhecimentos que têm relação com a estimulação do desenvolvimento da criança.

\section{Sono}

Nesta área se incluem os conhecimentos desejados pelas mães que tem relaçãc com horas de sono, posição e vestuário adequados para dormir.

\section{Necessidades afetivas}

Esta área compreende os conhecimentos desejados pelas mães relacionadas com carinho, amor e segurança proporcionados à criança.

\section{Higiene do ambiente físico}

Aqui foram incluídos os conhecimentos referentes aos aspectos considerados por ALCÂNTARA \& QUARENTEI ${ }^{2}$ sobre higiene do ambiente físico, assim como condições atmosféricas da habitação, clima, temperatura, umidade, ventos, grau de luminosidade, poeira e odores.

\section{Assuntos gerais}

Esta área abrange os conhecimentos desejados pelas mães, que não têm relação com nenhuma das áreas mencionadas.

\section{RESULTADOS E COMENTARIOS}

\section{Características da população}

A população estudada constituiu-se de 110 mães inscritas em um centro de saúde, no Programa Materno-Infantil, selecionadas segundo os critérios anteriormente descritos, e apresentando as seguintes características:

Idade - A maior parte da população $(71,8 \%)$ era constituída de mães de 15 a 25 anos, seguidas por $27,2 \%$, cuja idade variava de 25 a 35 anos.

Naturalidade - Considerando a naturalidade das mães de acordo com as regiões estabelecidas pelo $\mathrm{IBGE}^{3}$ acrescidas de países estrangeiros, verificou-se que $60,1 \%$ eram naturais da região sudeste e $50,9 \%$, da região nordeste. Em relação à naturalidade, mais de metade da população era natural do Estado de São Paulo, seguida de $17,2 \%$ do Estado da Bahia.

Estado civil - $81,8 \%$ das mães eram casadas.

Grau de instrução - Quase metade da população $(45,5 \%)$ estudou até a quarta série do primeiro grau. Apenas $9,0 \%$ não freqüentaram a escola.

Ocupação - A grande maioria da população $(96,4 \%)$ ocupava-se dos afazeres domésticos, apenas $3,6 \%$ trabalhavam fora de casa.

Renda mensal - 51,8\% das mães pertenciam a família de renda mensal entre um e dois salários mínimos (ano de 1979), apenas $26,4 \%$ enquadravam-se no grupo com renda de três a quatro salários mínimos.

Experiências anteriores no cuidado com 
criança - Identificou-se que $81,8 \%$ das mães nunca tiveram experiências no cuidado com crianças, antes de serem mães.

Idade das crianças - Verificou-se um nivelamento entre os percentuais, cujas crianças pertencem aos quatro grupos de idades a saber; zero a três meses; três a seis meses; seis a nove meses e nove a doze meses.

\section{Conhecimentos desejados pelas mães}

Foram em número de 803 as solicitações feitas pelas mães, nas várias áreas de conhecimento, sobre o cuidado com a criança.

Configuraram-se dez áreas de conhecimento que as mães gostariam de receber para o cuidado com o seu filho - alimentação $(22,6 \%)$; manifestações orgânicas ou af ecções comuns na infância $(15,9 \%)$; desenvolvimento $(14,4 \%)$; higiene corporal $(13,4 \%)$; crescimento $(11,0 \%)$; imunização $(11,0 \%)$; sono $(5,5 \%)$; necessidades afetivas $(2,4 \%)$; higiene do ambiente $(1,7 \%)$; assuntos gerais $(2,1 \%)$.

Dos conhecimentos sobre alimentação da criança, os mais freqüentemente solicitados foram relativos a tipos de alimentos que devem ser oferecidos à criança, como sopa, leite artificial, farinha para mingau, frutas, suco, chá, frutas para suco, sobremesas. A seguir, idade para introdução dos alimentos como sopa, ovo, mingau, peixe, sobremesa, fígado, papa de fruta, suco de fruta. A técnica para o preparo dos alimentos foi outro conhecimento desejado, em especial o preparo do mingau, sucos, sopa, ovo, tempo de fervura e de filtração da água.

$\mathrm{O}$ grupo de mães que apresentou o maior número de solicitações sobre $o$ assunto foi $o$ que possuia filhos da idade de zero a três meses, seguido do grupo de mães com criança de três a seis meses. Este fato pode ser explicado, porque, neste período de vida da criança, conforme destaca ALCÂNTARA ${ }^{1}$ várias mudanças se processam em sua alimentação, como a introdução de novos alimentos.

Diante destes dados, conclui-se que nos primeiros seis meses de vida da criança a mãe necessita de um comportamento mais efetivo por parte da equipe de saúde, a fim de esclarecer suas dúvidas e poder atender à criança nas suas mais variadas necessidades alimentares.

Dos conhecimentos solicitados sobre as manifestações orgânicas ou afecções comuns na infância, os mais freqüentes foram sobre tratamento: da alergia à roupa de lã, da assadura, bronquite, brotoejas, cólicas, coquelu- che, dor de ouvido, febre, fimose, gripe, prisão de ventre, etc. Prevenção: da assadura, bronquite, brotoeja, cólica, desidratação, dor de ouvido etc. Causas: de assadura, cólica, desidratação, resfriado, soluço. O maior número de solicitações feitas, sobre esse assunto, foi de mães com crianças de zero a três meses.

Os dados obtidos neste estudo demonstraram que há uma preocupação por parte das mães, em querer aprender a cuidar de criança, sobretudo quando apresenta uma manifestação ou afecção. Considerando esse interesse, a enfermeira, assim como toda a equipe de saúde, pode tornar afetiva uma das recomendações propostas pelo Ministério da $\mathrm{Saúde}^{6}$ (V Conferência Nacional de Saúde) que é de fornecer educação para saúde às mães, assim elas poderão participar melhor do tratamento da criança e ajudar na prevenção das possíveis causas das manifestações ou afecções, como parece ser o desejo demonstrado através dos dados obtidos.

Sobre o desenvolvimento da criança, destacou-se uma parte referente à estimulação do desenvolvimento e outra ao desenvolvimento propriamente dito. Sobre estimulação, as questões foram: 1) relativas a brinquedos: idade para introdução, tipos adequados à idade, tipos adequados ao sexo, explicação sobre preferência de determinados brinquedos; 2) idade para a criança ser estimulada a vestir-se sozinha, ir a escola, usar o piniquinho, andar, falar, dormir sozinha; 3) outros aspectos sobre estimulação como conceito de estimulação, meios de estimulação, locais adequados para a estimulação, importância e finalidade da estimulação. Sobre o desenvolvimento: conduta motora - quando começa a engatinhar, andar, a sentar-se sem ajuda, a dar os primeiros passos. Conduta pessoal-social: quando ajuda pôr os sapatos, brinca com as suas próprias mãos e pés, ajuda a vestir-se, reconhece os pais. Conduta da linguagem: entende o seu nome, diz as primeiras palavras. Conduta adaptativa: passa brinquedo de uma mão para outra, etc.

$\mathrm{O}$ grupo que apresentou o maior número de solicitações a respeito da estimulação e do desenvolvimento foi o de mães com crianças de nove a doze meses. Ao contrário das outras categorias de conhecimento, 0 interesse pelo assunto foi crescente, à medida que aumentou a idade das crianças.

A preocupação das mães a respeito do desenvolvimento da criança é explicada por MARLOW"13 "o desenvolvimento é um processo contínuo, começando antes do nascimento, 
e cada etapa depende de etapas anteriores". São modificações que se fazem progressiva e ordenadan.ente, porém a idade em que cada criança alcança a maturidade depende de sua "capacidade de maturação inerente, que atua reciprocamente com o seu meio ambiente físico e social".

Cabe então, com relação a esses aspectos, uma recomendação da autora acima citada, "a enfermeira pode interpretar aos pais o processo de desenvolvimento, aliviando em grande parte suas incompreensões".

Em relação a higiene corporal, a maior proporção de solicitações foi no que diz respeito ao banho da criança: técnica, número de banhos por dia, horário adequado, temperatura da água, duração do banho, finalidade etc., seguidos de higiene de partes do corpo: ouvido, boca, genitais femininos, olhos, nariz, pele, umbigo, genitais masculinos. Foi solicitado, ainda, idade para passeios ao sol, à praia, ao ar livre e banho de mar; e vestuário da criança: cuidados e freqüência de troca de roupas.

Em relação aos conhecimentos sobre a higiene corporal, observou-se que o maior número de solicitações foi feito pelas mães com criança de zero a três meses, e em especial sobre o banho do bebê.

Nas solicitações feitas nesta área de conhecimento, quando os mais variados assuntos são tratados, desde a maneira como vestir a criança e até o modo de segurá-las, ainda fica uma indagação: será que foi proporcionado um clima "permissivo" para as mães colocarem as suas dúvidas nos contatos que tiveram com os profissionais de saúde?

Quanto ao crescimento da criança, as questões se referiam tanto ao ganho de peso e altura em relação à idade, meios de avaliação do crescimento, fatores que favorecem o crescimento, relação entre quantidade de alimento e crescimento, quanto à dentição: início, sinais de erupção, limite de idade para erupção e relação entre diarréia e dentição, etc.

A respeito da imunização, a maior freqüência foi em saber idade para o emprego das vacinas (BCG, varíola, sarampo, Sabin, DPT); vacinas que a criança deve receber, finalidade das vacinas, cuidados necessários com - local vacinado, contra indicações para o emprego das vacinas, etc.

$\mathrm{O}$ interesse a respeito do assunto imunização foi evidente no grupo de mães com crianças de zero a três meses e, principalmente, sobre a idade para o emprego das vacinas. Verificou-se também que todas as solicitações feitas pelas mães estão relacionadas a aspectos do esquema de vacinação, o que constitui uma prioridade no atendimento das crianças de zero a doze meses.

LAURENTI ${ }^{11}$ chama atenção para $o$ fato de que parte dos óbitos ocorridos em São Paulo, poderiam ser evitados por meio de programas de vacinação.

A equipe de saúde tem um papel importante na diminuição de mortalidade, principalmente no atendimento às necessidades de conhecimentos das mães sobre 0 assunto imunização.

Sobre o sono, a freqüência de solicitações de conhecimentos foi bem menor que nas outras categorias, destacando-se apenas duas solicitações - horas de sono durante o dia; horas de sono durante a noite.

A necessidade de conhecimento a esse respeito é compreensível, considerando que a criança dorme praticamente o dia todo e a noite também no primeiro mês de vida, mas com o passar dos meses esse período vai diminuindo, o que poderá tornar a mãe preocupada.

ALCÂNTARA $^{1}$ explica que à proporção que a criança evolui, começa a dormir seguidamente apenas à noite e, durante o dia, dorme com intervalos. Entretanto, esse período vai diminuindo à medida que o desenvolvimento da criança lhe permite interesses cada vez maiores pelo ambiente.

As necessidades afetivas foram perguntadas de forma interessante pelas mães: Relação entre quantidade de carinho e os vários comportamentos da criança - criança mimada, criança manhosa, cheia de vontade, com maus costumes. Outras questões foram: Como evitar que a criança fique manhosa? Como satisfazer as necessidades afetivas da criança? Outras: relação entre ausência do pai e criança insegura.

O grupo que solicitou o maior número de conhecimentos sobre $o$ assunto foi o de mães com criança de zero a três meses. Entretanto, a reflexão sobre esse assunto merece ser despertada em mães com crianças de todas as idades, por considerar-se o assunto de importância valiosa, principalmente por ser 0 afeto uma necessidade; assim como a alimentação, hidratação, eliminação, a criança precisa sentir-se amada, isso contribui para o seu desenvolvimento e crescimento normais.

Dos conhecimentos sobre higiene do ambiente, destacou-se ambiente físico: ambiente ideal para o bem estar da criança, localização do quarto da criança, organização do quarto individual da criança e efeitos de ruídos for- 
tes, televisão, uso de inseticidas e saúde da criança.

Os dados apresentados mostraram que o grupo que solicitou maior número de conhecimentos sobre a higiene do ambiente, foi $o$ de mães de crianças de zero a três meses.

ALCÂNTARA \& QUARENTEI ${ }^{2}$ comentaram que "os componentes do ambiente físico da criança condicionam numerosos estímulos e solicitações favoráveis ou desfavoráveis à criança".

$\mathrm{O}$ ambiente onde a criança vive deve ser tema de orientação freqüente nos programas de saúde, considerando-se que para a criança ter saúde, assim como seus pais e familiares, tornam-se necessárias condições ambientais adequadas.

As questões categorizadas como assuntos gerais foram as seguintes: cuidados gerais com a criança nos primeiros meses de vida, finalidade do comparecimento ao centro de saúde e noções gerais sobre os diferentes tipos de choro.

As mães com crianças de zero a três meses foram as que solicitaram o maior número de conhecimentos sobre os cuidados gerais com a criança. A frequiência foi mínima, mas pode sugerir que haja um comportamento, mais efetivo, por parte da equipe de saúde, às mães, principalmente as primíparas. Esse mesmo grupo sugeriu que nos cursos que são ministrados durante o pré-natal, fossem abordados, também, os cuidados mínimos indispensáveis à criança nos primeiros meses de vida.

As respostas apresentadas com maior freqüência pelas mães para justificar o seu interesse em obter conhecimentos foram: "Quero receber orientação adequada"; "Não entendo bem as orientações que recebo"; "Não sei se é normal o que observo na criança"; "Quero aprender a cuidar da criança"; e "Cada um diz uma coisa diferente, fica-se em dúvida sempre".

A resposta correspondente ao desejo de receber orientação adequada constituiu, com maior freqüência, justificativa das mães para obter conhecimento na área da alimentação, assim como a justificativa de que não entendem bem as orientações que vêm recebendo.

As mães que responderam que não sabem se é normal o que observam na criança, referem-se principalmente às manifestações ou afecções comuns na infância e aos aspectos referentes ao desenvolvimento e ao crescimento da criança.

Entre as mães que responderam que querem aprender a cuidar corretamente da crian- ça, o maior número de respostas corresponde dos na área do desenvolvimento, seguidos dos à justificativa para os conhecimentos solicitaconhecimentos referentes ao sono da criança.

De modo geral, as justificativas apresentadas refletem que as mães estão desejosas de adquirir conhecimentos, motivadas pelo interesse de prestar cuidados às crianças, como também mostram que observam as manifestações que ocorrem na criança, e que querem compreendê-las, demonstrando seu interesse quanto aos aspectos preventivos das doenças.

\section{COMENTARIO FINAL}

Pelos resultados obtidos, verificou-se que as mães primíparas têm interesse em receber orientações. Esse interesse tanto pode estar ligado à vontade de aprender a cuidar da criança corretamente, como à necessidade de avaliação de si mesma, quanto aos conhecimentos que possui e/ou vem apresentando à criança.

Em todas as entrevistas notou-se a necessidade da mãe em poder falar de seu filho. des seus progressos e das dúvidas que tinha; além do que desejavam aprender, pareciairi também necessitar de um contato prolongado e humano.

Em sua maioria, as mães estavam acompanhadas com o pai da criança e este pareceu tão interessado quanto a mãe em termos de aprendizagem, tanto que em algumas ocasiões lembrou a mãe de dúvidas que tinham tido juntos. Este fato veio mostrar a necessidade de nas consultas de enfermagem, ser dada atenção também ao pai da criança.

Os dados apresentados demonstram que as mães primíparas têm necessidade de obter conhecimento e que esta necessidade é expressa quando lhes são dadas oportunidades. Tendo em vista a recomendação dos autores citados na introdução do trabalho, devem ser consideradas as necessidades de aprendizagem das mães, para que a orientação seja mais efetiva. Portanto, é conveniente que o enfermeiro, profissional mais envolvido com esta atividade, antes de realizar qualquer programa de orientação às mães, faça uma sondagem das suas dúvidas e dos seus interesses.

\section{CONCLUSAOO}

Tendo em vista o objetivo principal deste estudo, os resultados obtidos conduzem às seguintes conclusões:

- A necessidade de aprendizagem das mães foi evidenciada por meio de 803 solicita- 
ções, que correspondem a dez áreas de conhecimento: alimentação, manifestações orgânicas ou afecções comuns na infância, desenvolvimento, higiene corporal, imunização, crescimento, sono, necessidades afetivas, higiene do ambiente e outros assuntos.

- Os conhecimentos mais solicitados foram na área da alimentação, desenvolvimento, crescimento e manifestações orgânicas ou afecções comuns na infância.

- Os conhecidos com menor freqüência de solicitações foram necessidades afetivas e higiene do ambiente.

- Dentro de cada área de conhecimento, as mães gostariam de receber orientação, principalmente, sobre os seguintes aspectos: esquema alimentar da criança; tratamento, prevenção e causas das manifestações orgânicas ou afecções comuns na infância; comportamento esperado de acordo com a fase de desenvolvimento da criança; higiene da criança (banho); curva normal de crescimento; esquema de vacinação; horas de sono e efeitos do cuidado carinhoso sobre o comportamento da criança.

Quanto ao objetivo secundário identificaram-se:
- Maior interesse das mães com filhos de zero a três meses sobre conhecimentos relativos a manifestações orgânicas ou afecções na infância;

- No segundo e terceiro trimestre, os conhecimentos mais solicitados foram na área de alimentação e no quarto trimestre na área do desenvolvimento da criança;

- Constatou-se que quanto mais baixa a idade, maior o número de solicitações de conhecimentos apresentado pelas mães;

- A justificativa mais citada pelas mães para receber conhecimento, foi o interesse de prestar cuidados adequados às crianças.

Os resultados desta pesquisa podem ser aplicados eventualmente em centros de saúde, mas de maneira criteriosa, para evitar generalizações que, provavelmente, iriam contrariar as necessidades individuais de aprendizagem das mães.

LINDHOLM, R. R. Infant care during first year desirable knowledge of mothers. Rev. Bras. Enf., Brasília, 37(1): 36-43, 1984.

\section{REFERENCIAS BIBLIOGRAFICAS}

1. ALCANTARA, P. et alii. Pediatria preventiva. In: ALCANTARA, P. \& MARCONDES, E. Pediatria básica. 6. ed. São Paulo, Sarvier, 1978. v. 1, p. 103-54.

2. ALCANTARA, P. \& QUARENTI, G. Higiene do ambiente físico. In: ALCANTARA, P. \& MARCONDES, E. Pediatria básica. 4. ed. São Paulo, Sarvier, 1974. v. 1., p. 152.

3. ANUARIO ESTATISTICO DO BRASIL: 1976. Rio de Janeiro, Fundação IBGE, 1976. v. 37, p. 20.

4. BLAKE, F. G. El lactente: del mes al ano de vida. In: - Enfermeira pediátrica de Jeans. 8. ed. México, Interamericana, 1971. p. 206-46.

5. - Prevención de las enfermidades infantiles. In: - Enfermeria pediátrica de Jeans. 8. ed. México, Interamericana, 1971. p. 69.

6. BRASIL. Ministério da Saúde. V Conferência Nacional de Saude: programa materno-infantil. Brasília, 1975.

7. BRINTON, D. \& OGDEN, L. S. Pediatric experience in an ambulatory care setting. Nurs. Outlook, New York, 20 (6): 390-3, 1972.

8. DU GAS, B. W. Necessidade de aprendisaje del pacient. In: - Tratado de enfermeira prática de KOZIER. 2. ed. México, Interamericana, 1974. cap. 17 , p. $190-8$.

9. GESELLE, A. \& AMATRUDA, C. Diagnóstico del desarollo - normal y anormal del niño. Buenos Aires, Paidós, 1976. p. 35.

10. JELLIFE, D. B. La salud del niño en los trópicos: manual practico para el personal medico $y$ paramedico. Washington, Organização Panamericana de la Salud, 1966. (Publicação Científica, 133).
11. LAURENTI, R. Alguns aspectos particulares referentes aos resultados da investigação interamericana de mortalidade na infância na área do projeto de São Paulo, Brasil. Bol. Ofic. Sanit. Panamer., Washington, 79 (2): 1-14, jul. 1975.

12. MARCONDES, E. \& MACHADO, D. V. M. Crescimento e desenvolvimento. In: ALCANTARA \& MARCONDES, E. Pediatria básica. 6. ed. São Paulo, Sarvier, 1978. vol. 1., p. 45-67.

13. MARLOW, D. R. El lactente normal: crescimento desaroll y cuidado durante el primer año. In: - Enfermeira pediátrica. 4. ed., México, Interamericana, 1973. p. 299-347.

14. NATIONAL Comission for the study of nursing and nursing education apud BRINTON, D. \& OGDEN, L. S. Pediatric experience in an ambulatory care setting. Nurs Outlook, New York, 20 (6): 390-3, 1972.

15. ORGANIZACION PANAMERICANA DE LA SALUD. Enseñanza de enfermeria materno-infantil en las escuelas de enfermeria de America Latina. Washington, 1973. (Publicação Científica, 260).

16. OGUISSO, T. \& SCHMIDT, M. J. A propósito da classificação brasileira uniforme de ocupações. Rev. Bras. Enf., Brasília, 29 (2): 23, 1976.

17. PUFFER, R. R. \& SERRANO, C. Caracteristicas de la mortalidad en la niñez: informe de la investigación interamericana de mortalidad en la niñez. Washington, Organização Panamericana de la Salud, 1973. (Publicação Científica, 262).

18. RIDLE, I. I. Working with parents promove the well-being of children. In: CASTRO, F. The pediatric nurse practitioner. 2. ed. Saint Louis, Mosby, 1976. 